\title{
Can Biofortified Crops Help Attain Food Security?
}

\author{
Kathleen L. Hefferon ${ }^{1}$
}

Published online: 19 October 2016

(C) Springer International Publishing AG 2016

\begin{abstract}
Malnutrition, or "hidden hunger," continues to linger throughout the developing world. This is partially the result of a lack of access to a diversified diet. A burgeoning human population and the advent of climate change have resulted in the forecast of increases in food insecurity for at risk populations. The following report describes the use of agricultural biotechnology to generate crops which are biofortified with vitamins and minerals. Crops designed through biotechnology that possess additional health benefits such as preventing the onset of non-communicable diseases including hypertension and cancer are also presented. Examples of several biofortified and nutritionally enhanced crops are provided. The report ends with a discussion of the state of these technologies in the world today and their prospects for improving global food security.
\end{abstract}

Keywords Biofortified crop · Malnutrition · Agricultural biotechnology $\cdot$ Bioactive compound

\section{Introduction}

Malnutrition and hunger remain the biggest threats to mankind. While approximately 800 million people around the world are undernourished (meaning that they do not consume an adequate number of calories), over half of the world's population is malnourished (meaning that they lack access to

This article is part of the Topical Collection on Enhancing Agricultural Production.

Kathleen L. Hefferon

klh22@cornell.edu

1 Department of Food Sciences, Cornell University, Ithaca, NY, USA essential micronutrients such as vitamins and minerals). Most of the "food insecure," as they are referred to, are located in sub-Saharan Africa and Southeast Asia. Although the number of people living in extreme poverty (on less than $\$ 1.25$ a day) has steadily decreased over the past quarter century, the combination of rapid population growth and the precarious livelihoods of many of the rural poor has thrown the validity of economic improvements into question [1]. Often, rural farmers in developing countries find it difficult to recover from or be resilient to environmental shocks such as drought, excessive temperatures, or flooding. The advent of climate change will make these infrequent shocks even more numerous. Furthermore, the world's population is predicted to increase to 9-10 billion people by the middle of this century, with the vast majority of that increase taking place in developing countries. To keep up with the expected burgeoning population, agricultural productivity must double by 2050 . A year ago, the United Nations set out a series of Sustainable Development Goals which were intended to address, at the outset, global poverty and hunger. It was hoped that by addressing these goals initially, the most vulnerable would be lifted out of extreme poverty and could have the means to improve their general nutritional status by diversifying their diets with the wide range of micronutrients found in assorted fruits and vegetables.

In the middle of the twentieth century, the world faced a similar challenge of food security. As a result, a "Green Revolution" was launched. This included the introduction of new, high-yielding dwarf crop varieties, accompanied by synthetic inputs such as fertilizer and pesticides, as well as modern irrigation technologies into current agricultural practices [2].

The Green Revolution changed the fortune of India, which faced certain mass famine at that time, and improved cereal production in a matter of years, so that the country today has 
become a major exporter of cereal crops. Other developing countries such as China adapted similar strategies and also soon emerged as viable and strong economies [3]. Regardless of these changes in the past half century, subSaharan African agricultural development has largely remained stagnant to this day. At the moment, approximately one third of sub-Saharan Africans are undernourished and over half are malnourished, meaning that they lack the essential micronutrients essential for a healthy life [4]. Africa can expect to experience the consequences of climate change, and extreme heat and desertification are two forecasts for the continent over the next few decades. Even so, the population of Africa is expected to be more than double over the next 50 years. These factors will make agricultural land use and farming practices increasingly critical.

\section{Agricultural Biotechnology and Biofortified Crops}

Agricultural biotechnology refers to the use of new scientific techniques based on our understanding of DNA to improve crops and livestock that cannot be achieved through conventional breeding alone. Modern molecular plant breeding techniques such as marker assisted selection (MAS), for example, has enabled plant breeders to identify better traits in plants more rapidly than conventional breeding. Recombinant DNA technology, such as genetic engineering, can result in crops with new traits that cannot be achieved by conventional breeding practices [5]. Novel traits can be introduced into a crop through the manipulation of its genetic material. Foreign DNA can be incorporated into the plant genome either via Agrobacterium mediated transformation or by biolistic (gene gun) delivery. Transgenic or genetically modified (GM) crops have been commercially available in the USA since 1996. A well-known example of a GM food crop that produces a biofortified product is Golden Rice [6]. Golden Rice expresses $\beta$-carotene and is created philanthropically with the intent of alleviating vitamin A deficiency in developing countries. In this case, the genes introduced into the rice plant come from daffodil and a bacterium, species other than rice and not even derived from plantae, for that matter. For this reason, they are called transgenic plants. More recently, "cisgenic" plants, or plants which have genes included from the same species, have been under development. An example of a cisgenic plant would be a variety of American chestnut trees which are resistant to chestnut blight disease, due to the incorporation of a resistance gene from a related cousin, the Asian chestnut [7]. A third technology that falls under the umbrella of genetic engineering is RNA interference, or RNAi technology. In this case, the plant is designed to produce an antisense RNA to a particular gene, whose expression is then blocked via gene silencing. An example of the use of this technology includes genetically modified papayas, which are resistant to Papaya ringspot virus [8]. This technology is responsible for saving the Hawaiian papaya industry. More recently, a new technology known as "gene editing" has come to the forefront [9]. Gene editing does not require the introduction of new gene sequences, rather, it can employ only one or two nucleotide changes in a plant genome and, thus, is exempt from the regulations that govern the production of genetically modified organisms (GMOs). As a result, much research is being undertaken in the field of crop science and soon crops with improved agronomic traits, such as drought tolerance, higher yield, pest resistance, and improved nutritional content, will be realized in the near future.

\section{Biofortified and Nutritionally Enhanced Plants}

Much of the developing world consumes a monotonous diet of grain crops such as rice, wheat, or maize. The rural poor lack access to fresh fruits and vegetables, rich sources of vitamins, and minerals. Unfortunately, grains tend to not provide a full complement of micronutrients essential for human health. Common health deficiencies include vitamin A, folic acid, iron, zinc, and selenium [10, 11]. Deficiencies in these nutrients can lead to a variety of conditions such as anemia, can cause stunting, health defects, and can compromise the immune system.

Biofortification of crops through genetic engineering is considered by many to be more cost-effective than other supplementation strategies. Biofortified crops can be adapted through pre-existing seed and crop distribution channels and can be maintained by the farmers themselves. Supplementation of diets with vitamins and minerals in the form of pills or powders requires connecting reliably with a target population who may reside in a remote area. Supplementation also requires large investments and monitoring on a regular basis [3]. Increasing micronutrients through agronomic bioavailability, on the other hand, through the application of fertilizers on soil can also largely be successful, but depends on the mineral and crop species, cannot target specific edible plant organs, and cannot be an approach to provide vitamins or other bioactive compounds that requires synthesis by the plant. Similarly, conventional breeding for mineral dense varieties can be very time consuming and largely depends on the gene pool that pre-exists in a crop species $[12,13]$. Genetic engineering is often the only feasible option to increase micronutrient availability in a crop that does not produce that particular micronutrient, as is the case of $\beta$ carotene in rice grain. There are some caveats to producing biofortified crops, including regulatory restrictions, which could delay approval of the crop. Metabolic engineering of a biochemical pathway itself can be difficult to manage. The production of a desired compound may need to be increased, non-desirable or competitive endproducts may require 
downregulating, and, in certain instances, entirely new metabolic pathways must be synthesized in a plant that does not have the ability to accumulate that micronutrient.

The following provides a few examples of biofortified crops that have been generated through genetic modification.

\section{Biofortified Rice}

Vitamin A is essential for eye health as well as immune function, human development, and reproduction. Humans cannot synthesize vitamin A or its precursors, known as the carotenoids, and thus rely exclusively on dietary sources. Inadequate dietary intake leads to vitamin A deficiency (VAD), with pregnant women and young children being particularly vulnerable. Today, approximately 100-140 million children have VAD, and 250-500,000 will go blind as a result each year. Fifty percent of these will die within a year after losing their sight [14-16].

The endosperm of rice, a crop important to many VAD populations in the developing world, is white and does not accumulate carotenoids. Due to its long-reaching health benefits, rice biofortified with $\beta$-carotene was thus the first biofortifed crop to be developed. The first generation of Golden Rice was generated by reconstituting this biosynthetic pathway within the grain using genes from daffodil plants and a specific bacterium. Rice plants generated in this fashion were found to express $1.6 \mu \mathrm{g} \beta$-carotene/g dry weight in rice grains $[17,18]$. The next generation of Golden Rice technology, GR2, makes use of genes that are derived from two different $\beta$-carotene pathways and incorporates the maize phytoene synthesis gene in place of the same daffodil gene that was utilized in GR1 rice. GR2 Golden Rice can produce levels of $\beta$-carotene that reach $35 \mu \mathrm{g} / \mathrm{g}$ of dry rice. Golden Rice labeled with deuterium (by growing hydroponically in heavy water) was served in aliquots of 130-200 $\mathrm{g}$ and fed to human volunteers in levels of $0.99-1.53 \mathrm{mg} \beta$-carotene. Retinol levels were increased in volunteers' blood taken at 36 days after consumption to $0.34-0.94 \mu \mathrm{g}$ retinol. The results of this feeding study indicated that $\beta$-carotene that originates from Golden Rice is converted at a rate of $500-800 \mu \mathrm{g}$ retinol per $100 \mathrm{~g}$ rice. This amount approaches the recommended daily allowance for children. A different study illustrated that Golden Rice - derived $\beta$-carotene was more effective than spinach - derived $\beta$-carotene in providing children with vitamin A [19-23]. Based on these results, it was concluded that Golden Rice could provide relief to vitamin A-deficient populations in rice-consuming countries. Considered to be the first transgenic crop specifically engineered to combat malnutrition, Golden Rice could reach remote rural populations that lack access to supplementation programs. Rice has also been used as a food crop to prevent other forms of malnutrition, including folate and iron deficiencies. For example, [24] showed that transgenic biofortified rice would be more cost-effective in reducing folate deficiency than conventional supplementation programs that are currently in place [24].

\section{Biofortified Corn and Cassava}

While maize is capable of producing $\beta$-carotene, the variation of $\beta$-carotene content in different types of maize can be quite large. As a result, maize has been bred conventionally and genetically engineered to produce higher levels of $\beta$ carotene [25]. For example, $\beta$-carotene has been increased up to $59 \mu \mathrm{g} / \mathrm{g}$ dry weight in white endosperm varieties of transgenic maize. When this biofortified maize was consumed by North American women in the form of a porridge supplemented with oil, the conversion of $\beta$-carotene to retinol was determined to be $6.48+/=3.51 \mu \mathrm{g} \beta$-carotene $/ \mu \mathrm{g}$ retinol. Similarly, healthy Zimbabwean men fed with biofortified maize and supplemented with fat demonstrated a conversion of $3.2+/=1.5 \mu \mathrm{g} \beta$-carotene $/ \mu \mathrm{g}$ retinol [26-28]. Thus, $\beta$ carotene consumed in the form of biofortified maize can be absorbed and converted to retinol. Sorghum, a staple in Africa, has also been genetically modified to produce $\beta$ carotene through the use of the same transgenes that were employed to develop Golden Rice (GR2).

Cassava is the staple of a quarter of a billion sub-Saharan Africans, yet is nutritionally deficient in proteins, vitamins, and minerals. The BioCassava Plus project has been developed to generate high levels of $\beta$-carotene in cassava. Cassava expressing $\beta$-carotene and fed to healthy volunteers as a porridge increased $\beta$-carotene and plasma concentrations to $4.5 \mu \mathrm{g} \beta$-carotene $/ \mu \mathrm{g}$ retinol conversion, suggesting that biofortified cassava could prevent vitamin A deficiency. Programs such as these could therefore generate cassava crops with more lasting nutritional benefits. Since cassava roots express $<10-20 \%$ of the daily estimated amounts of zinc, iron, and vitamin $\mathrm{E}$, transgenic cassava biofortified with these micronutrients is also under development [29-31].

\section{Crops with Additional Health Benefits}

In addition to biofortification, crops with additional health benefits have been generated using biotechnology. Some of these are derived from phytochemicals and are of increasing interest due to their role in battling cardiovascular disease, cancer, hypertension, and diabetes; all considered to be leading causes of death in industrialized countries. Metabolic engineering of plants for improved health benefits includes the use of RNA interference (RNAi technologies), overexpression of promoters to increase gene expression, and the manipulation of transcription factors (TFs) to alter metabolic networks 
[5, 32-34]. A few examples of foods which have been nutritionally enhanced to produce increased amounts of phytochemicals are presented below.

\section{Nutritionally Enhanced Tomato}

Tomatoes, with their ease of growth and high consumption rates across the globe, are seen as good candidates for nutritional enhancement with phytochemicals. Tomatoes can produce nutraceuticals such as flavonoids and carotenoids, which have potential health benefits. For example, during tomato ripening, the red carotenoid lycopene accumulates to give tomatoes their red color. Other carotenoids such as $\beta$-carotene, lutein, and zeathanthin are produced in tomato fruit. The carotenoid pathway is complex, and a number of engineering steps are necessary to control the production of different metabolites. Several transgenic lines in tomato have been developed, for example the Red Setter line overexpresses Lcy-b, which in turn increases $\beta$-carotene production. Another transgenic line of tomato known as high Delta overexpresses Lyc-e to increase lutein content [35]. The metabolic engineering of the carotenoid pathway enables new plant sources to be used for the production of these biological compounds.

A metabolic engineering strategy involving the introduction of two transcription factors from snapdragon that are involved in anthocyanin production led to high levels of these flavonoids produced in tomato fruit, which became dark purple upon ripening. Tomato plants engineered to express the antioxidant anthocyanin, a bioactive compound that is found in blueberries and cranberries, were able to extend the life spans of mice susceptible to cancer by up to $30 \%$ [36]. These transgenic tomatoes, which also exhibit antiinflammatory properties, are thought to fight cardiovascular disease as well. For this reason, they are being tested on heart patients in the form of a juice [37]. Tomatoes were the fruit of choice due to the fact that they are affordable, available at all times of the year, and are consumed by large amounts of the population. Blueberries, on the other hand, tend to be seasonal and higher priced, therefore less accessible to consumers. Future tomatoes expressing anthocyanin may be sold in food products such as pizza sauce and ketchup.

Tomatoes again were the fruit of choice to be transformed with the gene encoding grape (Vitis vinifera L.) stilbene synthase. Transgenic tomatoes were able to accumulate trans-resveratrol, the bioactive compound found in red wine and grapes, but few other common food sources [38]. The transgenic lines exhibited significant increases in antioxidant capability and were able to counteract the pro-inflammatory effects of phorbol ester in monocyte-macrophage cultures [39, 40].

Flavonols are phytochemicals that have been shown to improve bone health. Transgenic tomato fruit expressing AtMYB12, a transcription factor from Arabidopsis, led to an increase in flavonol biosynthesis. Pre-pubertal mice fed transgenic tomatoes for 6 weeks exhibited significant increases in bone growth and density (both tibial and femoral) due to an increase in the number and size of hypertrophic chondrocytes. These tomatoes could enable individuals to better achieve peak bone mass during adolescence [41]. The genetic engineering of tomato is a feasible way to improve micronutrient accumulation for large and diverse populations as well as produce positive health benefits for growing animals.

\section{Nutritionally Enhanced Oil Crops}

Storage oils derived from plant seeds have been developed to produce novel types of fatty acids, such as those found in fish oils, that are beneficial to human health but absent from plantbased diets. These 'designer oilseed' crops have been metabolically engineered to produce omega-3 fatty acids (FA), which are important for brain function and development as well as cardiovascular health [42]. The oceans have largely undergone overfishing, and since much of omega $-3 \mathrm{FA}$ is derived from marine life, genetically modified plants can provide a source of this nutrient that is sustainable. Transgenic algae are also under development to express levels of omega-3 FA resembling those found in marine life. This fatty acid metabolic pathway has been reconstituted in oilseed crops such as false flax, a direct relative of canola [43]. A number of other beneficial fatty acids produced in plant seed oils by metabolic engineering include $\gamma$-linolenic acid, stearidonic acid, and arachidonic acid [44, 45].

\section{Conclusions}

It is tempting to imagine that nutritionally enhanced crops could play a significant role in reducing global malnutrition; however, several concerns must be dealt with. Paramount is the issue of how public perception and international policy will influence biotech crop regulation in the future [46]. Under today's regulatory environment, GM crops must undergo rigorous risk assessment which centers on detailed molecular characterization of the crop, assessment of toxicity and/or allergenicity, and nutritional content. In Europe, this process has become hindered by the imposition of the precautionary principle guidelines of regulation, which takes the position that GM crops should not be easily made available because they cannot be inherently proven to be safe. This organization of the current European regulatory program has created a suspension of GM crop approval across the EU, thus preventing the development of nutritionally enhanced crops advancing for philanthropic purposes. In spite of this moratorium, in 2013, a record of 175.2 million hectares of biotech crops were grown [47]. The fact that farmers who try 
out GM crops replant them from one year to the next provides a strong indicator that farmers are pleased with this technology's performance. It is important to note that over $90 \%$ of those who planted transgenic crops are poor small shareholder farmers living in developing countries, thereby contradicting the assertion by some that GM crops are used only by industrialized countries [47].

In keeping with the Sustainable Development Goals set last fall, it is paramount that biofortified crops, made with genetic engineering technology, be developed and provided to the rural poor to alleviate malnutrition. Recently, a strong letter, signed by 100 Nobel laureates and delivered to Greenpeace, has spelled out how narratives against genetically engineered crops damage the world's most needy. Biofortifed crops, developed through modern technology, has a place in the solution to global food insecurity [48].

\section{Compliance with Ethical Standards}

Conflict of Interest Kathleen L. Hefferon declares that she has no conflicts of interest.

Human and Animal Rights and Informed Consent This article does not contain any studies with human or animal subjects performed by any of the authors.

\section{References}

1. International Food Policy Research Institute, 2014, Global Hunger Index

2. Bazuin S, Azadi H, Witlox F. Application of GM crops in subSaharan Africa: lessons learned from green revolution. Biotechnol Adv. 2011;29(6):908-12.

3. Bhutta ZA, Salam RA, Das JK. Meeting the challenges of micronutrient malnutrition in the developing world. Br Med Bull. 2013;106:7-17.

4. Gilani GS, Nasim A. Impact of foods nutritionally enhanced through biotechnology in alleviating malnutrition in developing countries. J AOAC Int. 2007;90(5):1440-4.

5. Pérez-Massot E, Banakar R, Gómez-Galera S, et al. The contribution of transgenic plants to better health through improved nutrition: opportunities and constraints. Genes Nutr. 2013;8(1):29-41.

6. Farre G, Twyman RM, Zhu C, et al. Nutritionally enhanced crops and food security: scientific achievements versus political expediency. Curr Opin Biotechnol. 2011;22(2):245-51

7. Newhouse AE, Polin-McGuigan LD, Baier KAV, et al. Transgenic American chestnuts show enhanced blight resistance and transmit the trait to T1 progeny. Plant Sci. 2014;228:88-97.

8. Lin HT, Yen GC, Lee WC, et al. J Agric food Chem. 2015.

9. Chiang Z, Zhang K, Chen K, et al. Targeted mutagenesis in Zea mays using TALENs and the CRISPR/Cas system. J Genet Genomics. 2014;41(2):63-8.

10. Pachón H, Ortiz DA, Araujo C, et al. Iron, zinc, and protein bioavailability proxy measures of meals prepared with nutritionally enhanced beans and maize. J Food Sci. 2009;74(5):H147-54
11. Das JK, Kumar R, Salam RA, et al. Systematic review of zinc fortification trials. Ann Nutr Metab. 2013;62(Suppl 1):44-56.

12. Rayman MP, Infante HG, Sargent M. Food-chain selenium and human health: spotlight on speciation. Br J Nutr. 2008;100(2): 238-53.

13. Dai JL, Zhu YG, Zhang M, et al. Selecting iodine-enriched vegetables and the residual effect of iodate application to soil. Biol Trace Elem Res. 2004;101:265-76.

14. Al-Babili S, Beyer P. Golden Rice - five years on the road - five years to go? Trends Plant Sci. 2005;10(12):565-73.

15. Beyer P. Golden Rice and 'Golden' crops for human nutrition. New Biotechnol. 2010;27(5):478-81.

16. Haskell MJ. The challenge to reach nutritional adequacy for vitamin a: $\beta$-carotene bioavailability and conversion - evidence in humans. Am J Clin Nutr. 2012;96(5):1193S-203S.

17. Federico ML, Schmidt MA. Modern breeding and biotechnological approaches to enhance carotenoid accumulation in seeds. Subcell Biochem. 2016;79:345-58.

18. Paine JA, Shipton CA, Chaggar S, et al. Improving the nutritional value of golden Rice through increased pro-vitamin a content. Nat Biotechnol. 2005;23(4):482-7.

19. Potrykus I. Lessons from the 'Humanitarian golden Rice' project: regulation prevents development of public good genetically engineered crop products. New Biotechnol. 2010;27(5):466-72.

20. Alós E, Rodrigo MJ, Zacarias L. Manipulation of carotenoid content in plants to improve human health. Subcell Biochem. 2016;79: 311-43.

21. De Moura FF, Palmer AC, Finkelstein JL, et al. Are biofortified staple food crops improving vitamin a and iron status in women and children? New evidence from efficacy trials. Adv Nutr. 2014;5(5): 568-70.

22. Tang G, Qin J, Dolnikowski GG, et al. Golden Rice is an effective source of vitamin a. Am J Clin Nutr. 2009;89(6):1776-83.

23. Chang $\mathrm{G}, \mathrm{Hu} \mathrm{Y}$, Yin $\mathrm{SA}$, et al. $\beta$-carotene in golden Rice is as good as $\beta$-carotene in oil at providing vitamin A to children. Am J Clin Nutr. 2012;96(3):658-64.

24. De Steur H, Blancquaert D, Strobbe S, et al. Status and market potential of transgenic biofortified crops. Nat Biotechnol. 2015;33(1):25-9.

25. Muzhingi T, Gadaga TH, Siwela AH, et al. Yellow maize with high $\beta$-carotene is an effective source of vitamin A in healthy Zimbabwean men. Am J Clin Nutr. 2011;94:510-9.

26. Li SS, Nugroho A, Rocheford T, et al. Vitamin A equivalence of the $\beta$-carotene in $\beta$-carotene-biofortified maize porridge consumed by women. Am J Clin Nutr. 2010;92:1105-12.

27. Moretti D, Biebinger R, Bruins MJ, et al. Bioavailability of iron, zinc, folic acid, and vitamin A from fortified maize. Ann N Y Acad Sci. 2014;1312:54-65.

28. Mugode L, Há B, Kaunda A, et al. Carotenoid retention of biofortified provitamin a maize (Zea mays L.) after Zambian traditional methods of milling, cooking and storage. J Agric Food Chem. 2014;62(27):6317-25.

29. Pillay K, Siwela M, Derera J, et al. Provitamin A carotenoids in biofortified maize and their retention during processing and preparation of south African maize foods. J Food Sci Technol. 2014;51(4):634-44. doi:10.1007/s13197-011-0559-x.

30. De Moura FF, Miloff A, Boy E. Retention of Provitamin A Carotenoids in Staple Crops Targeted for Biofortification in Africa: Cassava, Maize and Sweet Potato. Crit Rev Food Sci Nutr. 2013.

31. Sayre R, Beeching JR, Cahoon EB, et al. The BioCassava plus program: biofortification of cassava for sub-Saharan Africa. Annu Rev Plant Biol. 2011;62:251-72.

32. McGloughlin MN. Modifying agricultural crops for improved nutrition. New Biotechnol. 2010;27(5):494-504. 
33. Wilson SA, Roberts SC. Metabolic engineering approaches for production of biochemicals in food and medicinal plants. Curr Opin Biotechnol. 2014;26:174-82.

34. Pandey A, Misra P, Khan MP, et al. Co-expression of Arabidopsis transcription factor, AtMYB12, and soybean isoflavone synthase, GmIFS1, genes in tobacco leads to enhanced biosynthesis of isoflavones and flavonols resulting in osteoprotective activity. Plant Biotechnol J. 2014;12(1):69-80.

35. D'Ambrosio C, Stigliani AL, Giorio G. Food from genetically engineered plants tomato with increased $\beta$-carotene, lutein, and Xanthophylls contents. In: Watson R, Preedy V, editors. Genetically modified organisms (GMO) foods: production, safety. Amsterdam: Regulation and Public Health. Elsevier; 2016. p. 35360 .

36. Gonzali S, Mazzucato A, Perata P. Purple as a tomato; towards high anthocyanin tomatoes. Trends Plant Sci. 2009;14:237-41.

37. Butelli E, Titta L, Giorgio M, et al. Enrichment of tomato fruit with health-promoting anthocyanins by expression of select transcription factors. Nat Biotechnol. 2008;26(11):1301-8.

38. Giovinazzo G, D'Amico L, Paradiso A, et al. Antioxidant metabolite profiles in tomato fruit constitutively expressing the grapevine stilbene synthase gene. Plant Biotechnol J. 2005;3(1):57-69.

39. Ingrosso I, Bonsegna S, De Domenico S, et al. Over-expression of a grape stilbene synthase gene in tomato induces parthenocarpy and causes abnormal pollen development. Plant Physiol Biochem. 2011;49(10):1092-9.
40. D'Introno A, Paradiso A, Scoditti E, et al. Antioxidant and antiinflammatory properties of tomato fruits synthesizing different amounts of stilbenes. Plant Biotechnol J. 2009;7(5):422-9.

41. Choudhary D, Pandey A, Adhikary S, Ahmad N, et al. Genetically engineered flavonol enriched tomato fruit modulates chondrogenesis to increase bone length in growing animals. Sci Rep. 2016;6:21668.

42. Haslam RP, Ruiz-Lopez N, Eastmond P, et al. The modification of plant oil composition via metabolic engineering-better nutrition by design. Plant Biotechnol J. 2013;11(2):157-68.

43. Ruiz-López N, Haslam RP, Venegas-Calerón M, et al. Enhancing the accumulation of omega-3 long chain polyunsaturated fatty acids in transgenic Arabidopsis thaliana via iterative metabolic engineering and genetic crossing. Transgenic Res. 2012a;21(6):1233-43.

44. Ruiz-López N, Sayanova O, Napier JA, et al. Metabolic engineering of the omega-3 long chain polyunsaturated fatty acid biosynthetic pathway into transgenic plants. J Exp Bot. 2012b;63(7): 2397-410.

45. Ruiz-Lopez N, Haslam RP, Napier JA, et al. Successful high-level accumulation of fish oil omega-3 long-chain polyunsaturated fatty acids in a transgenic oilseed crop. Plant J. 2014;77(2):198-208.

46. Potrykus I. Regulation must be revolutionized. Nature. 2010;466(7306):561.

47. James, C. Global Status of Commercialized Biotech/GM Crops. 2014 ISAAA Reports

48. 107 Nobel laureates sign letter blasting Greenpeace over GMOsThe Washington Post, 2016. 